\title{
Inflammasomes and Their Role in Innate Immunity of Sexually Transmitted Infections
}

\author{
Vivek Verma ${ }^{1}$, Rakesh Singh Dhanda ${ }^{2}$, Niels Frimodt Møller ${ }^{3}$ and Manisha Yadav ${ }^{1,3 *}$ \\ ${ }^{1}$ Dr. B. R. Ambedkar Center for Biomedical Research, University of Delhi, New Delhi, India, ${ }^{2}$ Department of Translational and \\ Regenerative Medicine, Post Graduate Institute of Medical Education and Research (PGIMER), Chandigarh, India, \\ ${ }^{3}$ Department of Clinical Microbiology, Rigshospitalet, Copenhagen, Denmark
}

OPEN ACCESS

Edited by:

Laurel L. Lenz,

University of Colorado Denver

School of Medicine, USA

Reviewed by:

Tiago W. P. Mineo,

Federal University of

Uberlandia, Brazil

Rebecca Leigh Schmidt,

Upper lowa University, USA

*Correspondence:

Manisha Yadav

manisha.dhanda@gmail.com

Specialty section:

This article was submitted to

Microbial Immunology,

a section of the journal

Frontiers in Immunology

Received: 27 August 2016 Accepted: 16 November 2016 Published: 05 December 2016

Citation:

Verma V, Dhanda RS, Møller NF and Yadav M (2016) Inflammasomes and

Their Role in Innate Immunity of Sexually Transmitted Infections.

Front. Immunol. 7:540. doi: 10.3389/fimmu.2016.00540
Inflammasomes are multiprotein complexes present in the cytosol as pattern recognition receptors or as sensors of damage-associated molecular patterns. After recognition of microbe-associated molecular patterns or host-derived danger signals, nucleotide oligomerization domain-like receptors oligomerize to form inflammasomes. The activation of inflammasomes results in an alarm, which is raised to alert adjacent cells through the processing and release of a number of other substrates present in the cytosol. A wide array of inflammasomes and their adapter molecules have been identified in the host's innate immune system in response to various pathogens. Components of specific pathogens activate different inflammasomes, which once activated in response to pathogen-induced infection, induce the activation of caspases, and the release of mature forms of interleukin-1 $\beta(\mathrm{IL}-1 \beta)$ and IL-18. Identifying the mechanisms underlying pathogen-induced inflammasome activation is important if we are to develop novel therapeutic strategies to target sexually transmitted infections (STIs) related pathogens. This information is currently lacking in literature. In this review, we have discussed the role of various inflammasomes in sensing different STIs, as well as the beneficial or detrimental effects of inflammasome signaling in host resistance. Additionally, we have discussed both canonical and non-canonical processing of IL-1 $\beta$ induced with respect to particular infections. Overall, these findings transform our understanding of both the basic biology and clinical relevance of inflammasomes.

Keywords: innate immunity, inflammasomes, NOD-like receptors, sexually transmitted infections, host defense, pathogens

\section{INTRODUCTION}

Innate immune receptors act as the first line of defense against infectious microbes, continuously monitoring the extracellular milieu as well as subcellular compartments. These receptors can either be extracellular, such as some of the toll-like receptors (TLR) and C-type lectin receptors (CLR), or intracellular, such as nucleotide oligomerization domain (NOD)-like receptors (NLR), retinoic-acid-inducible gene (RIG-I)-like receptors (RLR), and AIM2 (absent in melanoma 2)-like receptors (ALR). Cytosolic immune receptors not only act as pattern recognition receptors (PRRs) that recognize pathogen-associated molecular patterns (PAMPs) but also sense signals derived from the host commonly known as damage-associated molecular patterns (DAMPs). These include 
intracellular molecules such as ATP and high-mobility group box 1 (HMGB1) protein as well as proteins derived from extracellular matrix. These PRRs trigger a downstream signaling cascade in the presence of specific ligands, resulting in the activation of transcription machinery inducing the production and release of pro-inflammatory cytokines. These cytokines further regulate the switch between tissue homeostasis and the inflammatory state, aimed at the removal of pathogens thus restoring normal tissue function (1).

Inflammasomes are multiprotein complexes consisting mainly of NLR, ASC (apoptosis-associated speck-like protein), and caspase-1, which are formed upon activation by specific ligands. NLRs are cytosolic protein receptors, and under highly regulated conditions, they assemble with ASC and caspase-1 to form speck-like aggregates $(2,3)$. The composition of inflammasomes varies in response to different ligands, for example, NLRP1 is a sensor of muramyl dipeptide (MDP: toxin of Bacillus anthracis) (4), NLRP3 responds to various cytosolic insults such as reactive oxygen species (ROS) (5), cathepsin B release (6), pore forming toxins [PFTs: nigericin (7)], extracellular crystals (8), and NLRC4 that oligomerizes in response to the presence of flagellin and PrgJ rod proteins within the cytoplasm (9). PYHIN (pyrin containing HIN200 domain) containing AIM2 and IFI16 (interferon- $\gamma$ inducible protein 16) initiates the formation of the inflammasome in response to foreign cytoplasmic double-stranded DNA (10, 11). Initially suggested as sensors of a microbial infection (12), inflammasomes have recently emerged as central orchestrators of microbial infections (13).

Aberrantly high inflammasome activation and abrogation of inflammasome signaling in different tissues leads to the development of various inflammatory pathologies, indicating the necessity of a finely balanced signaling cascade and a downstream cytokine release. Initial regulation of inflammasome activity occurs through transcriptional/posttranslational control. As a consequence of this, inflammasome expression levels are usually low in most cell types at the steady state. A stimulus (for example, extracellular PRR signaling) is required for induction of the inflammasome gene transcription and is known as signal 1 or priming $(14,15)$. Inflammasome formation then depends on the activation of specific NLR triggers, referred to as signal 2. Many potential inflammasome stimulators are now known, such as microbe-derived substances, molecules related to endogenous damage, and environmental particles (16).

Inflammasomes recruit and activate pro-inflammatory caspases, which result in the cleavage of pro-forms of IL- $1 \beta$ and IL-18 into mature and secretable forms. Each inflammasome contains ASC, an adaptor protein for caspase activation and a recruitment domain (CARD); however, NLRC4 contains a CARD domain that itself interact with caspase-1. Furthermore, inflammasome activity is tightly regulated since it leads to the production of some of the most potent pro-inflammatory cytokines (IL-1 $\beta$ and IL-18) and the subsequent induction of inflammatory cell death, pyroptosis (12). Inflammasome-mediated processes act as a key factor for clearance of infections and regulation of various metabolic and immune processes. In the past decade, inflammasome research has intensified with regards to various metabolic and infectious diseases. However, the mechanisms behind the stimulus of inflammasome assembly during sexually transmitted infections (STIs) are poorly understood.

Sexually transmitted infections are one of the most highly prevalent infections, with 340 million new cases every year worldwide, of which $50 \%$ are among adolescents and young adults (17). Most of these STI cases are reported in developing nations, mainly South Asia, Southeast Asia, Sub-Saharan Africa, Latin America, and the Caribbean (18). STIs impose huge economic losses every year because of its high incidence (19). STDs cost the U.S. health-care system an amount of $\$ 15.9$ billion annually (20). Though STIs caused by bacterial, mycological, and protozoan agents can be treated successfully, all the viral STIs are not treatable with current medications. STIs not only cause intense morbidity in adults but also lead to intense complications such as infertility, ectopic pregnancy, fetal wastage, premature birth, low birth weight, premature mortality, cervical tumor, inborn syphilis, and ophthalmia neonatorum (21). The effect of inflammasome signaling during the development of various STIs has not been adequately studied. Here, we review the recent progress of our understanding of inflammasome signaling and the consequences of defective inflammasome activation during various STIs.

\section{CHLAMYDIA INFECTION}

Chlamydia trachomatis, an obligate intracellular Gram-negative human pathogen, is a leading cause of bacterial STI and preventable blindness worldwide. C. trachomatis infects both men and women and inflicts a wide range of diseases including conjunctivitis, urethritis, ectopic pregnancy, and infertility in the affected women. Infection of pregnant women can be passed on to the baby during pregnancy or childbirth, causing conjunctivitis or fatal pneumonia in the newborn. Chlamydia affects 90 million new cases each year worldwide (22).

The pathogenesis of the Chlamydia infection and the resulting inflammatory process have been examined using multiple animal models and in vitro studies (22). The infection is initiated by the attachment and entry of elementary bodies (EBs) into epithelial cells that transit into replicative reticulate bodies (RBs) to establish a parasitophorous vacuole, also known as inclusion (23). C. trachomatis employs a type III secretion system (T3SS) and encodes a chlamydial protease-like activity factor (CPAF) to establish a replicative niche within host cells $(24,25)$. Response to an epithelial cell infection occurs within a few days and is characterized by neutrophil infiltration, which kills accessible EBs, followed by an accumulation of T-cells and other leukocytes in the infected area (26). The inflammatory process resulting from primary infection often results in either long-term tissue damage or tubal damage and infertility (22).

Chlamydia trachomatis activates the NLRP3 inflammasome in an ASC and caspase-1-dependent manner in diverse human and mouse cells (27-30). However, the role of non-NLRP3 inflammasomes during infection cannot be totally refuted. In a recent animal study, a murine model of Chlamydia muridarum infection shows interferon (IFN)-inducible guanylate-binding protein (GBP)-dependent pyroptosis through activation of caspase-11-dependent non-cannonical and caspase-1-dependent 
cannonical inflammasomes (NLRP3 and AIM2) (31). In $N L R P 3^{-1-}$ - and $A S C^{-1-}$-deficient mice, survival of Chlamydia and caspase-1-dependent IL-18 secretion (32) were reduced, and lipid droplets were accumulated showing evidence of promotion of atherosclerosis and metabolic diseases (33). In another study, $A p o E^{-l-}$ (Apolipoprotein E)-deficient mice fed on high fat diet and infected with Chlamydia resulted in accelerated atherosclerosis with a presence of activated myeloid DCs (mDCs) and plasmacytoid DCs (pDCs) (34). In a report from Nagarajan et al., mice deficient in IL-1R showed delayed clearance of Chlamydia, supporting the role of IL-1 $\beta$ in infection clearance, but they suggested a low significance of inflammasome pathways in IL-1 $\beta$ secretion and genital tract pathologies (32). Particularly pORF5, a secretory protein of Chlamydia sp. has been found to facilitate the secretion of IL-1 $\beta$ and IL-18 through NALP3 activation (35).

In mouse bone marrow macrophages, the AIM2 inflammasome contributes partially to the production of IL- $1 \beta$ and IL-18 during the infection (31). Thus, prior exposure of C. trachomatisinfected THP-1 cells to anti-oxidants partially inhibits IL- $1 \beta$ secretion, reinforcing the fact that multiple upstream mechanisms or inflammasomes may be involved (30). Thus, multiple pathways including non-TLRs contribute to IL- $1 \beta$ production equally. Evidence suggests a role of NOD1 in IL- $1 \beta$ secretion from a human trophoblast cell line exposed to Chlamydia (36).

Contrary to the protective function of the NLRP3 upon infection with the respiratory pathogen Chlamydia pneumoniae (37), caspase- 1 activation promotes the growth of $C$. trachomatis in cervical epithelial cells (29). The finding mentioned in the former study is supported at least partially by the observed inflammasomemediated pyroptosis of Chlamydia-exposed antigen presentation cells, which are critical in Chlamydia clearance (38). However, a later study has its own limitations as the results were obtained in $I L-10^{-/-}$dendritic cells (DCs) and no direct observations were made in cells lacking inflammasome components. Nevertheless, $I L-10$ deficiency does result in enhanced inflammasome activation $(39,40)$. Contrary to the results in cervical epithelial cells, Caspase- $1^{-1-}$ mice exhibit similar C. trachomatis growth in the urogenital tracts (41). However, a Caspase-1 deficiency results in significantly reduced inflammatory damage, suggesting that inflammasomes may not be directly controlling the C. trachomatis infection in vivo per se, but caspase-1 activation can invoke the Chlamydia-induced inflammatory pathologies in the genital tract (41) (Table 1; Figure 1).

\section{Candidiasis}

Candidiasis is a well-known fungal infection caused by the yeast Candida with more than 20 different types known so far. Candida albicans is a well-tolerated resident of mucosal surfaces of the gastrointestinal and urogenital tract in most healthy people. However, an overgrowth of C. albicans can lead to an invasion of the epithelium causing oropharyngeal candidiasis (thrush) or genital/vulvovaginal candidiasis (yeast infection). The "yeast infection" is so common that nearly $75 \%$ of all adult women have at least one infection in their lifetime. Additionally, during primary and/or secondary immunodeficiency, yeast is the primary cause of opportunistic infections causing mucocutaneous candidiasis and occasionally systemic sepsis (51).

The cell wall architecture of Candida is well characterized and is deemed essential for the biology and pathogenicity of C. albicans (52). It consists of three basic constituents: $\beta$-glucans, chitin, and mannoproteins. $\beta$-glucans and chitin represent the structural components and provide physical properties to the cell wall (52). $\beta$-glucans and mannans display the most potent immunomodulatory activity leading to NLRP3 inflammasome activation and IL- $1 \beta$ secretion in mouse macrophages and human monocytes (53). The transcriptional upregulation of IL-1 $\beta$ is attained by

TABLE 1 | Different inflammasomes activated during STIs and their respective stimulus.

\begin{tabular}{|c|c|c|c|c|c|}
\hline S. no. & Organism/disease & $\begin{array}{l}\text { Inflammasome } \\
\text { activated }\end{array}$ & Ligands and activation stimulus & $\begin{array}{l}\text { Experimental } \\
\text { model }\end{array}$ & Reference \\
\hline 1 & $\begin{array}{l}\text { Chlamydia } \\
\text { trachomatis }\end{array}$ & NLRP3, NOD 1 & $\begin{array}{l}\text { Type third secretion system (T3SS), chlamydial protease-likeactivity factor } \\
\text { (CPAF) }\end{array}$ & $\begin{array}{l}\text { Monocytes, dendritic } \\
\text { cells }\end{array}$ & $(27-30)$ \\
\hline 2 & $\begin{array}{l}\text { Candida albicans: } \\
\text { candidiasis }\end{array}$ & NLRP3, NLRC4 & $\begin{array}{l}\text { Hyphae formation induces IL-1 } \beta \text { secretion, syk signaling activates NLRP3 } \\
\text { through CARD9, C. albicans infection activated NLRC4 in mucosal } \\
\text { stromal cells }\end{array}$ & $\begin{array}{l}\text { Monocytes-derived } \\
\text { macrophages and } \\
\text { dendritic cells }\end{array}$ & $(42-44)$ \\
\hline 3 & HIV: AIDS & NLRP3 & $\begin{array}{l}\text { Pro IL-1 } 1 \beta \text { expression occurs through TLR8-dependent mechanism } \\
\text { and IL-1 } 1 \beta \text { processing is done by NLRP3 activation, which occurred by } \\
\text { HIV- } 1 \text {-induced ROS generation and cathepsin B release from disrupted } \\
\text { lysosomes }\end{array}$ & $\begin{array}{l}\text { Thp1-derived } \\
\text { macrophages and } \\
\text { peripheral blood } \\
\text { mononuclear cells }\end{array}$ & $(45)$ \\
\hline 4 & $\begin{array}{l}\text { Herpes simplex virus: } \\
\text { genital herpes }\end{array}$ & $\begin{array}{l}\text { IFI16 (AIM2-like } \\
\text { receptors) }\end{array}$ & Cytosolic DNA sensed by IFI16 & $\begin{array}{l}\text { Thp1-derived } \\
\text { macrophages }\end{array}$ & $(11)$ \\
\hline 5 & $\begin{array}{l}\text { Human papilloma } \\
\text { virus }\end{array}$ & $\begin{array}{l}\text { IFI16 and AIM2, } \\
\text { NLRP3 }\end{array}$ & $\begin{array}{l}\text { IFI16 and AIM2 sense viral DNA present in cytosol, Cathepsin B release } \\
\text { and ROS generation activates NLRP3 }\end{array}$ & $\begin{array}{l}\text { Keratinocytes, Thp1 } \\
\text { cells }\end{array}$ & $(46,47)$ \\
\hline 6 & $\begin{array}{l}\text { Haemophilus ducreyi: } \\
\text { chancroid }\end{array}$ & AIM2 and NLRP3 & ROS generation, $\mathrm{K}^{+}$efflux, Cathepsin B activity, and lysosome acidification & MDM, Thp1-cells & $(48)$ \\
\hline 7 & $\begin{array}{l}\text { Neisseria gonorrhoea: } \\
\text { gonorrhea }\end{array}$ & NLRP3 & N. gonorrhoea activates Cathepsin B which is responsible for NLRP3 & $\begin{array}{l}\text { Thp1, PBMC-derived } \\
\text { macrophages }\end{array}$ & $(49)$ \\
\hline 8 & $\begin{array}{l}\text { Treponema pallidum: } \\
\text { syphilis }\end{array}$ & - & Activation by extracellular ATP followed by binding to $P 2 \Xi 7$ receptor & $\begin{array}{l}\text { PBMC-derived } \\
\text { macrophages }\end{array}$ & (50) \\
\hline
\end{tabular}




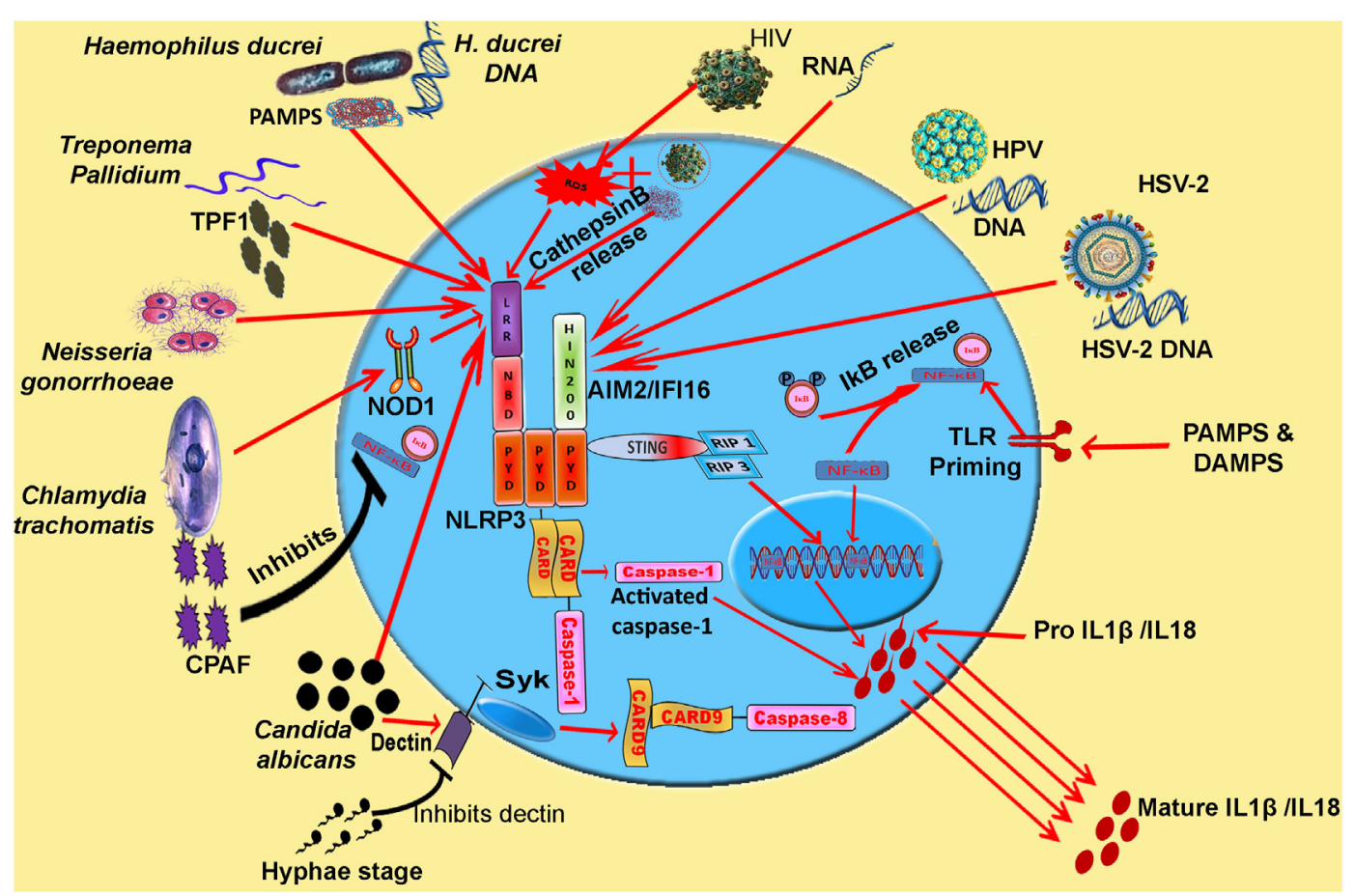

FIGURE 1 | Model: inflammasome activation and pro-inflammatory cytokine release during various STIs. Synchronization of various inflammasomes and their adapters in the regulation of pro-inflammatory cytokine release. Cytosolic DNA and viral RNA of various viruses (HIV, HSV-2, and HPV) and different pathogens are sensed by AIM2 inflammasome. PAMPs and DAMPs of Haemophilus ducreyi, Neisseria gonorrhoeae, and TPF1 (Treponema pallidum factor-1) of Treponema pallidum trigger NLRP3 inflammasome. CPAF protease of Chlamydia trachomatis inhibits NF-kB signaling and pathogen triggers NLRP3 signaling via Nod 1 adapter. IL-1 $\beta$ release resulting from Candida albicans infection is mediated by caspase-8 activation. Abbreviations: NLRP, Nod-like receptor protein; NLRC4, Nod-like receptor containing CARD4; AIM2, absent in melanoma 2; IFI16, interferon inducible; LPS, lipopolysaccharide; MDP, muramyl dipeptide; PFTs, pore forming toxins; ROS, reactive oxygen species.

Dectin-1, TLR2, and mannose receptor signaling upon recognition of specific Candida cell wall components, known as signal 1 in case of candidiasis (54). Inflammasome-mediated IL- $1 \beta$ secretion is essential in mounting a protective Th17 response that is central for the activation of mucosal antifungal immunity (55-57). In agreement, mice inept at sensing $C$. albicans demonstrate an enhanced dissemination of a mucosal infection and significant mortality in vivo (58). Activation of the NLRP3 inflammasome is mediated by a two-signal mechanism. However, the tyrosine kinase syk, functioning downstream of Dectin-1, couples both the two signals during a C. albicans infection. The syk/CARD9 pathway upregulates IL-1 $\beta$ production $(59,60)$, while sykmediated ROS production and potassium efflux enable caspase-1 and inflammasome activation, resulting in IL-1 $\beta$ maturation (53). These studies suggest that syk and NLRP3 are critical in controlling C. albicans infection. Mice lacking either syk or NLRP3 demonstrate an enhanced fungal burden and mortality $(53,61)$. Furthermore, targeted deletion studies suggest a key importance of syk in CD11 $\mathrm{c}^{+}$cells during systemic candidiasis (61) implying that NLRP3 activation in CD11 $\mathrm{c}^{+}$cells governs candidiasis.

Ligation of dectin-1 with specific antigens assembles inflammasomes independent of caspase-1. Exposure of DCs to curdlan and certain C. albicans strains assembles the Dectin-1 triggered CARD-9-Bcl-10-MALT1 scaffold for IL-1 $\beta$ transcription. At the same time, Dectin-1 initiates recruitment of MALT1-caspase-8 and ASC into this scaffold leading to caspase-8 (56)-dependent pro-IL-1 $\beta$ cleavage. This suggests that distinct downstream signaling pathways can possibly also be triggered through the same receptor suggesting the diversity of immune pathways and their activation mechanisms. It is likely that the affinity of receptorligand interactions dictates these discrete signaling outcomes. Contrary to the previous belief, the caspase-8/NLRP3 inflammasome can be initiated independent of pathogen internalization. However, activation of NLRP3 is ambiguous in this setting, and it is possible that either fungi or their secreted toxins progress to the cytoplasm. The emergences of non-canonical and non-redundant inflammasomes for pro-IL- $1 \beta$ processing emphasize the diversity and versatility of the immune response to pathogens (56).

The precursor form of IL- $1 \beta$ can be cleaved by several proteases; however, it is still surprising that CARD-containing caspase- 8 can substitute for caspase- 1 in the inflammasome considering that no other caspase family member is known to do so (62). Secreted aspartic proteases (Sap), a family of extracellular proteases released by Candida, also triggers IL- $1 \beta$ and IL-18 maturation dependent on $\mathrm{K}^{+}$efflux and ROS production (44). Particularly, Sap 4-6 proteases activate NLRP3-triggered IL-1 $\beta$ secretion in vaginal fluid and recruit polymorphonuclear neutrophils (PMNs) during C. albicans intravaginal challenge (63). 
On the other hand, endocytosis of Sap stimulates the caspase-11 inflammasome through type I IFN signaling (64). Thus, Sap proteins serve as trigger factors for both canonical and noncanonical inflammasomes.

Dimorphic Candida switches from the yeast form (blastoconidia) to filamentous forms (hyphae) during decreased oxygen tension or limiting nutrients (65). Filamentous hyphal forms of Candida are considered virulent since they facilitate adhesion and penetration of epithelial and endothelial cells (65). The hyphal form has also been suggested to be essential for the activation of the NLRP3 inflammasome (42). However, whether this is sufficient enough is not clear since certain morphologically similar mutants induce lower levels of IL-1 $\beta$ than wild-type $C$. albicans. More importantly, certain mutants defective in hyphae formation trigger comparable levels of IL- $1 \beta$ secretion, thus implying that other microbial and host mechanisms are more likely to contribute to activating inflammasome assembly (66). In a murine model of oropharayngeal candidiasis, NLRP3 in either the hematopoietic/stromal compartments and epithelial NLRC4 play an important role in immune resistance to Candida, by mounting pro-inflammatory and antimicrobial responses (43). However, whether this is indeed true during intravaginal challenge is still not clear. It has been argued that recurrent episodes of symptomatic infection in women, which are associated with immune hyperreactivity to the fungus lead to exaggerated pathological inflammation and a robust vaginal PMN migration. This is driven by NLRP3 and epithelial NLRC4 activity, which is important during vaginal challenge and ineffective inflammation. A robust vaginal PMN migration occurs in susceptible women, promoting pathological inflammation without affecting fungal burden due to NLRP3 activation (67). Thus, during a vaginal challenge, both NLRP3 and NLRC4 were activated. While NLRP3 contributes to neutrophil recruitment and pathogenic inflammation, IL-22-induced pNLRC4 restricts NLRP3 by a sustained production of IL-1Ra (67). This suggests that while NLRP3 activity is critical in controlling systemic dissemination of the infection, NLRC4 activity in stromal cells is required for the protection from mucosal candidiasis (Table 1; Figure 1).

\section{Human Immunodeficiency Virus}

Human immunodeficiency virus (HIV) is a retrovirus (ssRNA virus) that causes persistent inflammation and acute immune activation, which is a primary characteristic of this disease that contributes to the development of acquired immune deficiency syndrome (AIDS) $(68,69)$. The virus causes an infection with the transfer of body fluids from an infected person to another, which includes semen, vaginal fluids, breast milk, and blood. In its new host, the virus uses the envelope glycoprotein gp 120 to attach to a CD4 receptor found on T-cells, monocytes, and macrophages. Around 35 million individuals are infected with HIV worldwide (70).

Polymorphisms in genes encoding NLRP3 and IL-1 $\beta$ have been observed in susceptible patients (71). However, the transcriptional profile of genes encoding inflammasome components in HIV patients is still under debate. HIV-positive patients display a similar transcriptional expression of inflammasome genes in peripheral blood mononuclear cells (PBMCs) compared with controls (72). However, ex vivo studies show that DCs obtained from HIV-1 patients are unresponsive as compared to an elevated mRNA expression of NLRP 3 , caspase- 1 , and IL- $1 \beta$ in control DCs (73). Having said that patient DCs possess an enhanced basal expression of NLRP3 and the unresponsiveness to a subsequent infection might be due to the saturation in NLRP3 gene levels or due to a chronic inflammatory state of these cells (73).

In monocytes and macrophages, HIV-1 is sensed by TLR8 leading to inflammasome activation, and this is not accompanied by type I IFN production $(45,74)$. This is an infection-independent mechanism and reveals utilization of distinct TLRs by different cell types for type I IFN or inflammasome pathways of inflammation. Interestingly, HIV-1 replication steps including entry, reverse transcription and integration, but not virion maturation, were all required, and HIV-1-induced ROS and cathepsin B also were necessary for the activation of NLRP3 inflammasome (45). The primary cause for progression to AIDS is the progressive loss of CD4 T cells, which might be due to inflammasome-induced pyroptosis, an inflammatory form of programed cell death (75). Cell-to-cell transmission of HIV is required for activation of caspase-1-dependent pyroptosis, and cell-free HIV-1 virions fail to induce pyroptosis (76) (Table 1; Figure 1).

\section{Genital Herpes}

A crucial viral disease caused by herpes simplex virus type 1 (HSV-1) and type 2 (HSV-2) is known as genital herpes. Oral herpes is the most common form of this disease with visibly clear symptoms such as facial or oral infections and cold sores. Genital herpes is the second most common form of herpes infection (77). The specific clinical characteristics of herpes infections are painful ano-genital ulceration. HSV-1 and HSV-2 are the cause of oro-labial ulcers and ulcerative lesions, respectively, in adult populations (77). HSV-1-infected cells mediate the induction of IFN in which IFI16 and the murine protein p204 play an indispensable role (11). During HSV-2 infection, STING activates the NF- $\mathrm{KB}$ pathway (signal 1 ) to produce pro IL-1 $\beta$ through RIP1 and RIP3 (receptor-interacting protein). The viral DNA is sensed by the IFI16 inflammasome (signal 2), which oligomerizes to activate caspase- 1 to convert pro-IL- $1 \beta$ into mature IL-1 $\beta$ (Table 1; Figure 1).

\section{Human Papilloma Viruses}

The human papilloma viruses (HPVs) are non-enveloped, doublestranded DNA viruses that are the principle cause of benign warts and infections of the ano-genital region. Recent advancements in $\mathrm{HPV}$-associated research led to the discovery of approximately 180 types of HPVs (78). The most common HPVs such as HPV-6 and HPV-11 constitute a $100 \%$ protective quadrivalent vaccine agent against genital warts infection (79).

A human papilloma virus activates the AIM2 inflammasome through viral DNA recognition. Additionally, another DNA sensor, IFI6, is activated resulting in IFN- $\gamma$ release. The presence of the two DNA sensors and the active forms of caspase- 1 and IL- $1 \beta$ are detectable in HPV-positive skin lesions, in which the virus selectively infects keratinocytes in stratified epithelia. However, the two DNA sensors seem to negate the effect of the other as 
blocking one of the sensors potentiates responses from the other in experiments performed in normal human keratinocytes (46). Whether and what role HPV does play in these processes is unclear from the current studies and a detailed understanding of these molecular pathways is required to develop improved strategies for the prevention and treatment of HPV infections (Table 1; Figure 1).

\section{Chancroid}

Haemophilus ducreyi (Gram-negative, cocci) is a causative agent of the genital ulcer disease known as chancroid. The disease is prevalent in certain underdeveloped regions of Africa, Asia, and the Caribbean. Infection levels are very low in the developed countries and are mainly reported among individuals who have traveled outside these countries to affected regions.

Haemophilus ducreyi infection activates the inflammasome in monocyte-derived macrophages and experimentally infected human skin (48). Secretion of NLRP3-dependent IL-1 $\beta$ in macrophages is dependent on both caspase- 1 and caspase- 5 . However, these results have been observed with caspase- 1 and caspase- 5 inhibitors, and further studies using genetic knockdown tools are required to substantiate this data. Interestingly, this activation is limited to M1 and M2 macrophages while non-polarized macrophages fail to activate inflammasomes, suggesting that the precise contribution of inflammasomes in human lesions cannot be directly extrapolated (48) (Table 1; Figure 1).

\section{Gonorrhea}

Neisseria gonorrhoeae is a Gram-negative diplococcus that can grow and rapidly multiply in the mucous membranes especially in the mouth, throat, anus, cervix, fallopian tubes, and uterus of the infected individuals. Gonorrhea represents an estimated 60 million cases of urethritis and cervicitis every year around the world (80).

Even before inflammasome was first characterized, distinct immortalized epithelial cell lines from human endocervix, ectovervix, and vagina were demonstrated to secrete IL-1 $\beta$ and other pro-inflammatory cytokines when exposed to piliated $N$. gonorrhoeae $(81,82)$. Later studies revealed the identity of the NLRP3 inflammasome involved in causing pyronecrosis and HMGB1 release in macrophages in a cathepsin B-dependent manner. Hexa-acylated lipid A lipooligosaccharide, a N. gonorrhoeae virulence factor, activates the NLRP3 inflammasome (83). However, the phagosomal disruption and penetrance of host cytosol by $N$. gonorrhoeae as possibly activating NLRP3 cannot be completely ruled out (49) (Table 1; Figure 1).

\section{Syphilis}

Treponema pallidum, a spirochete bacterium causing syphilis, is a well-known STI. Despite the fact that the essential course of transmission is through sexual activities, it is also transmitted to the fetus from mother either during pregnancy or at the time of childbirth, thus increasing chances of induced congenital syphilis. Protease resistant antigen T. pallidum factor-1 (AgTpF1) is found to be involved in the stimulation of monocytes resulting in the release of pro-inflammatory cytokines such as TNF- $\alpha$, IL-6, and IL-1 $1 \beta$. The IL-1 $\beta$ release was found to be particularly due to the inflammasome activation at early stages of syphilis infection (50). In a syphilis infection, Bacterioferritin protein TpF1 of $T$. pallidum activates the NLRP3 inflammasome to mediate the cleavage of pro IL-1 $\beta / 18$ into a mature and bioactive form of IL-1 $\beta / 18$ (Table 1; Figure 1).

\section{Urinary Tract Infection}

Urinary tract infections (UTIs) are mostly caused by uropathogenic Escherichia coli (UPEC). UTIs affect at least $60 \%$ of all women once in their lifetime. UPEC virulence includes proteins that function in immune evasion, fimbriae, toxins, iron uptake, and biofilms. Innate immune responses are induced by neutrophils, antimicrobial peptides, and PRRs such as NLRs.

Despite several studies of the function of TLRs in UTI, the role of NLRs in UTI has not been elucidated. One of the few studies in the murine model of cyclophosphamide (CP) induced cystitis, glyburide suggested to suppress caspase- 1 with reduction in the release of IL-1 $\beta$; whereas NLRP3 inhibition blocks bladder dysfunction in CP model (84). The coordinated response of NLRs and TLRs in the urothelia represented a first line of innate defense. Another study identified a protective role of autophagy gene ATG16L1 deficiency in UPEC-induced UTIs (85) and inflammasome activation is known to inhibit autophagy by regulating the secretion of IL-1 $\beta$. NOD2 was found to be dispensable in the pathogenesis of UTIs in mice as well. Species and strain-specific inflammasome activation was found to be partially dependent on NLRP3 in human macrophages and completely in mouse macrophages (86).

\section{CONCLUSION AND FUTURE PERSPECTIVES}

While our understanding of inflammasomes and their various regulatory mechanisms has increased tremendously in the last decade, we have only scratched the surface in terms of inflammasome activation during urinary and STIs. UTI-causing species belonging to genus Enterococcus, Klebsiella, and Staphylococcus induce NLRP3 inflammasome activation leading to excessive secretion of IL-1 $\beta$ and cell death in macrophages (87-91). However, the role of inflammasomes and the mechanism behind their activation are still unknown, due to the limited knowledge in this field. This is partly due to the lack of appropriate animal models available to study UTIs and STIs. However, many laboratories are now actively working on the function of NLR in innate immunity of the UTI patients. It is essential to understand which inflammasomes play a critical role in UTIs and STIs; what their activation mechanisms are; and how these multiprotein complexes sense a wide array of alterations in a cell type-specific manner. This knowledge will potentially lead to an improved therapeutic and diagnostic approach for treating a range of infections.

\section{AUTHOR CONTRIBUTIONS}

MY and VV: conceived and designed the idea. VV: online searches and data collection. MY, VV, RSD, and NFM: preparation of manuscript, and editing and proofreading of final manuscript. 


\section{ACKNOWLEDGMENTS}

This study was supported by grants from the Department of Science and Technology (No: SR/FT/LS-117/2011) and the

\section{REFERENCES}

1. Medzhitov R. Origin and physiological roles of inflammation. Nature (2008) 454(7203):428-35. doi:10.1038/nature07201

2. Jones JD, Dangl JL. The plant immune system. Nature (2006) 444(7117):323-9. doi:10.1038/nature05286

3. Martinon F, Mayor A, Tschopp J. The inflammasomes: guardians of the body. Annu Rev Immunol (2009) 27:229-65. doi:10.1146/annurev. immunol.021908.132715

4. Boyden ED, Dietrich WF. Nalplb controls mouse macrophage susceptibility to anthrax lethal toxin. Nat Genet (2006) 38(2):240-4. doi:10.1038/ng1724

5. Cruz CM, Rinna A, Forman HJ, Ventura AL, Persechini PM, Ojcius DM. ATP activates a reactive oxygen species-dependent oxidative stress response and secretion of proinflammatory cytokines in macrophages. J Biol Chem (2007) 282(5):2871-9. doi:10.1074/jbc.M608083200

6. Hornung V, Bauernfeind F, Halle A, Samstad EO, Kono H, Rock KL, et al. Silica crystals and aluminum salts activate the NALP3 inflammasome through phagosomal destabilization. Nat Immunol (2008) 9(8):847-56. doi:10.1038/ ni. 1631

7. Hentze H, Lin XY, Choi MS, Porter AG. Critical role for cathepsin B in mediating caspase-1-dependent interleukin-18 maturation and caspase-1-independent necrosis triggered by the microbial toxin nigericin. Cell Death Differ (2003) 10(9):956-68. doi:10.1038/sj.cdd.4401264

8. Dostert C, Pétrilli V, Van Bruggen R, Steele C, Mossman BT, Tschopp J. Innate immune activation through Nalp3 inflammasome sensing of asbestos and silica. Science (2008) 320(5876):674-7. doi:10.1126/science.1156995

9. Zhao Y, Yang J, Shi J, Gong YN, Lu Q, Xu H, et al. The NLRC4 inflammasome receptors for bacterial flagellin and type III secretion apparatus. Nature (2011) 477(7366):596-600. doi:10.1038/nature 10510

10. Bürckstümmer T, Baumann C, Blüml S, Dixit E, Dürnberger G, Jahn H, et al. An orthogonal proteomic-genomic screen identifies AIM2 as a cytoplasmic DNA sensor for the inflammasome. Nat Immunol (2009) 10(3):266-72. doi: $10.1038 /$ ni. 1702

11. Unterholzner L, Keating SE, Baran M, Horan KA, Jensen SB, Sharma S, et al. IFI16 is an innate immune sensor for intracellular DNA. Nat Immunol (2010) 11(11):997-1004. doi:10.1038/ni.1932

12. Schroder K, Tschopp J. The inflammasomes. Cell (2010) 140(6):821-32. doi:10.1016/j.cell.2010.01.040

13. Henao-Mejia J, Elinav E, Strowig T, Flavell RA. Inflammasomes: far beyond inflammation. Nat Immunol (2012) 13(4):321-4. doi:10.1038/ni.2257

14. Franchi L, Eigenbrod T, Nunez G. Cutting edge: TNF-alpha mediates sensitization to ATP and silica via the NLRP3 inflammasome in the absence of microbial stimulation. J Immunol (2009) 183(2):792-6. doi:10.4049/ jimmunol.0900173

15. Bauernfeind FG, Horvath G, Stutz A, Alnemri ES, MacDonald K, Speert D, et al. Cutting edge: NF-kappaB activating pattern recognition and cytokine receptors license NLRP3 inflammasome activation by regulating NLRP3 expression. JImmunol (2009) 183(2):787-91. doi:10.4049/jimmunol. 0901363

16. Heneka MT, Kummer MP, Stutz A, Delekate A, Schwartz S, Vieira-Saecker A, et al. NLRP3 is activated in Alzheimer's disease and contributes to pathology in APP/PS1 mice. Nature (2013) 493(7434):674-8. doi:10.1038/ nature 11729

17. WHO. Global Strategy for the Prevention and Control of Sexually Transmitted Infections: 2006-2015: Breaking the Chain of Transmission. Geneva: World Health Organization (2007).

18. WHO. Global Prevalence and Incidence of Curable STIs. Geneva: World Health Organization (WHO/CDS/CDR/EDC/2001.10) (2001).

19. Mayaud P, Mabey D. Approaches to the control of sexually transmitted infections in developing countries: old problems and modern challenges. Sex Transm Infect (2004) 80(3):174-82. doi:10.1136/sti.2002.004101
Department of Biotechnology (No: BT/PR6301/GBD/27/396/ 2012) to MY. CSIR fellowship to VV and R\&D grant from University of Delhi, Delhi (No: RC/2015/9677) to MY is greatly acknowledged.

20. Chesson HW, Blandford JM, Gift TL, Tao G, Irwin KL. The estimated direct medical cost of sexually transmitted diseases among American youth, 2000. Perspect Sex Reprod Health (2004) 36(1):11-9. doi:10.1363/3601104

21. Sorce S, Krause KH. NOX enzymes in the central nervous system: from signaling to disease. Antioxid Redox Signal (2009) 11(10):2481-504. doi:10.1089/ ARS.2009.2578

22. Hybiske K, Stephens RS. Mechanisms of Chlamydia trachomatis entry into nonphagocytic cells. Infect Immun (2007) 75(8):3925-34. doi:10.1128/ IAI.00106-07

23. Byrne GI, Ojcius DM. Chlamydia and apoptosis: life and death decisions of an intracellular pathogen. Nat Rev Microbiol (2004) 2(10):802-8. doi:10.1038/ nrmicro1007

24. Betts HJ, Wolf K, Fields KA. Effector protein modulation of host cells: examples in the Chlamydia spp. arsenal. Curr Opin Microbiol (2009) 12(1):81-7. doi:10.1016/j.mib.2008.11.009

25. Valdivia RH. Chlamydia effector proteins and new insights into chlamydial cellular microbiology. Curr Opin Microbiol (2008) 11(1):53-9. doi:10.1016/j. mib.2008.01.003

26. Barteneva N, Theodor I, Peterson EM, de la Maza LM. Role of neutrophils in controlling early stages of a Chlamydia trachomatis infection. Infect Immun (1996) 64(11):4830-3.

27. Gervassi A, Alderson MR, Suchland R, Maisonneuve JF, Grabstein KH, Probst P. Differential regulation of inflammatory cytokine secretion by human dendritic cells upon Chlamydia trachomatis infection. Infect Immun (2004) 72(12):7231-9. doi:10.1128/IAI.72.12.7231-7239.2004

28. Lu H, Shen C, Brunham RC. Chlamydia trachomatis infection of epithelial cells induces the activation of caspase- 1 and release of mature IL-18. J Immunol (2000) 165(3):1463-9. doi:10.4049/jimmunol.165.3.1463

29. Abdul-Sater AA, Koo E, Häcker G, Ojcius DM. Inflammasome-dependent caspase-1 activation in cervical epithelial cells stimulates growth of the intracellular pathogen Chlamydia trachomatis. J Biol Chem (2009) 284(39):26789-96. doi:10.1074/jbc.M109.026823

30. Abdul-Sater AA, Saïd-Sadier N, Padilla EV, Ojcius DM. Chlamydial infection of monocytes stimulates IL-1beta secretion through activation of the NLRP3 inflammasome. Microbes Infect (2010) 12(8-9):652-61. doi:10.1016/ j.micinf.2010.04.008

31. Finethy R, Jorgensen I, Haldar AK, de Zoete MR, Strowig T, Flavell RA, et al. Guanylate binding proteins enable rapid activation of canonical and noncanonical inflammasomes in Chlamydia-infected macrophages. Infect Immun (2015) 83(12):4740-9. doi:10.1128/IAI.00856-15

32. Nagarajan UM, Sikes JD, Yeruva L, Prantner D. Significant role of IL-1 signaling, but limited role of inflammasome activation, in oviduct pathology during Chlamydia muridarum genital infection. J Immunol (2012) 188(6):2866-75. doi:10.4049/jimmunol.1103461

33. Itoh R, Murakami I, Chou B, Ishii K, Soejima T, Suzuki T, et al. Chlamydia pneumoniae harness host NLRP3 inflammasome-mediated caspase-1 activation for optimal intracellular growth in murine macrophages. Biochem Biophys Res Commun (2014) 452(3):689-94. doi:10.1016/j.bbrc.2014. 08.128

34. Sorrentino R, Yilmaz A, Schubert K, Crother TR, Pinto A, Shimada K, et al. A single infection with Chlamydia pneumoniae is sufficient to exacerbate atherosclerosis in ApoE deficient mice. Cell Immunol (2015) 294(1):25-32. doi:10.1016/j.cellimm.2015.01.007

35. Cao W, Zou Y, Su S, He Z, Liu Y, Huang Q, et al. Chlamydial plasmid-encoded protein pORF5 induces production of IL-1beta and IL-18 via NALP3 inflammasome activation and p38 MAPK pathway. Int J Clin Exp Med (2015) 8(11):20368-79.

36. Kavathas PB, Boeras CM, Mulla MJ, Abrahams VM. Nod1, but not the ASC inflammasome, contributes to induction of IL-1beta secretion in human trophoblasts after sensing of Chlamydia trachomatis. Mucosal Immunol (2013) 6(2):235-43. doi:10.1038/mi.2012.63 
37. Shimada K, Crother TR, Karlin J, Chen S, Chiba N, Ramanujan VK, et al. Caspase-1 dependent IL-1beta secretion is critical for host defense in a mouse model of Chlamydia pneumoniae lung infection. PLoS One (2011) 6(6):e21477. doi:10.1371/journal.pone.0021477

38. Omosun Y, McKeithen D, Ryans K, Kibakaya C, Blas-Machado U, Li D, et al. Interleukin-10 modulates antigen presentation by dendritic cells through regulation of NLRP3 inflammasome assembly during Chlamydia infection. Infect Immun (2015) 83(12):4662-72. doi:10.1128/IAI.00993-15

39. Greenhill CJ, Jones GW, Nowell MA, Newton Z, Harvey AK, Moideen AN, et al. Interleukin-10 regulates the inflammasome-driven augmentation of inflammatory arthritis and joint destruction. Arthritis Res Ther (2014) 16(4):419. doi:10.1186/s13075-014-0419-y

40. Gurung P, Li B, Subbarao Malireddi RK, Lamkanfi M, Geiger TL, Kanneganti TD. Chronic TLR stimulation controls NLRP3 inflammasome activation through IL-10 mediated regulation of NLRP3 expression and caspase-8 activation. Sci Rep (2015) 5:14488. doi:10.1038/srep14488

41. Cheng W, Shivshankar P, Li Z, Chen L, Yeh IT, Zhong G. Caspase-1 contributes to Chlamydia trachomatis-induced upper urogenital tract inflammatory pathologies without affecting the course of infection. Infect Immun (2008) 76(2):515-22. doi:10.1128/IAI.01064-07

42. Joly S, Ma N, Sadler JJ, Soll DR, Cassel SL, Sutterwala FS. Cutting edge: Candida albicans hyphae formation triggers activation of the Nlrp3 inflammasome. J Immunol (2009) 183(6):3578-81. doi:10.4049/jimmunol.0901323

43. Tomalka J, Ganesan S, Azodi E, Patel K, Majmudar P, Hall BA, et al. A novel role for the NLRC4 inflammasome in mucosal defenses against the fungal pathogen Candida albicans. PLoS Pathog (2011) 7(12):e1002379. doi:10.1371/ journal.ppat.1002379

44. Pietrella D, Pandey N, Gabrielli E, Pericolini E, Perito S, Kasper L, et al. Secreted aspartic proteases of Candida albicans activate the NLRP3 inflammasome. Eur J Immunol (2013) 43(3):679-92. doi:10.1002/eji.201242691

45. Guo H, Gao J, Taxman DJ, Ting JP, Su L. HIV-1 infection induces interleukin-1beta production via TLR8 protein-dependent and NLRP3 inflammasome mechanisms in human monocytes. J Biol Chem (2014) 289(31):21716-26. doi:10.1074/jbc.M114.566620

46. Reinholz M, Kawakami Y, Salzer S, Kreuter A, Dombrowski Y, Koglin S, et al. HPV16 activates the AIM2 inflammasome in keratinocytes. Arch Dermatol Res (2013) 305(8):723-32. doi:10.1007/s00403-013-1375-0

47. Gram AM, Frenkel J, Ressing ME. Inflammasomes and viruses: cellular defence versus viral offence. J Gen Virol (2012) 93(10):2063-75. doi:10.1099/ vir.0.042978-0

48. Li W, Katz BP, Bauer ME, Spinola SM. Haemophilus ducreyi infection induces activation of the NLRP3 inflammasome in nonpolarized but not in polarized human macrophages. Infect Immun (2013) 81(8):2997-3008. doi:10.1128/ IAI.00354-13

49. Duncan JA, Gao X, Huang MT, O'Connor BP, Thomas CE, Willingham SB, et al. Neisseria gonorrhoeae activates the proteinase cathepsin $\mathrm{B}$ to mediate the signaling activities of the NLRP3 and ASC-containing inflammasome. J Immunol (2009) 182(10):6460-9. doi:10.4049/jimmunol.0802696

50. Babolin C, Amedei A, Ozolins D, Zilevica A, D’Elios MM, de Bernard M. TpF1 from Treponema pallidum activates inflammasome and promotes the development of regulatory T cells. J Immunol (2011) 187(3):1377-84. doi:10.4049/ jimmunol.1100615

51. Dimopoulos G, Karabinis A, Samonis G, Falagas ME. Candidemia in immunocompromised and immunocompetent critically ill patients: a prospective comparative study. Eur J Clin Microbiol Infect Dis (2007) 26(6):377-84. doi:10.1007/s10096-007-0316-2

52. Chaffin WL, López-Ribot JL, Casanova M, Gozalbo D, Martínez JP. Cell wall and secreted proteins of Candida albicans: identification, function, and expression. Microbiol Mol Biol Rev (1998) 62(1):130-80.

53. Gross O, Poeck H, Bscheider M, Dostert C, Hannesschläger N, Endres S, et al. Syk kinase signalling couples to the Nlrp3 inflammasome for anti-fungal host defence. Nature (2009) 459(7245):433-6. doi:10.1038/nature07965

54. van de Veerdonk FL, Joosten LA, Devesa I, Mora-Montes HM, Kanneganti TD, Dinarello CA, et al. Bypassing pathogen-induced inflammasome activation for the regulation of interleukin- $1 \beta$ production by the fungal pathogen Candida albicans. J Infect Dis (2009) 199(7):1087-96. doi:10.1086/597274

55. Cheng SC, van de Veerdonk FL, Lenardon M, Stoffels M, Plantinga T, Smeekens S, et al. The dectin-1/inflammasome pathway is responsible for the induction of protective T-helper 17 responses that discriminate between yeasts and hyphae of Candida albicans. J Leukoc Biol (2011) 90(2):357-66. doi:10.1189/jlb.1210702

56. Gringhuis SI, Kaptein TM, Wevers BA, Theelen B, van der Vlist M, Boekhout T, et al. Dectin-1 is an extracellular pathogen sensor for the induction and processing of IL-1beta via a noncanonical caspase- 8 inflammasome. Nat Immunol (2012) 13(3):246-54. doi:10.1038/ni.2222

57. van de Veerdonk FL, Joosten LA, Shaw PJ, Smeekens SP, Malireddi RK, van der Meer JW, et al. The inflammasome drives protective Th1 and Th17 cellular responses in disseminated candidiasis. Eur J Immunol (2011) 41(8):2260-8. doi:10.1002/eji.201041226

58. Hise AG, Tomalka J, Ganesan S, Patel K, Hall BA, Brown GD, et al. An essential role for the NLRP3 inflammasome in host defense against the human fungal pathogen Candida albicans. Cell Host Microbe (2009) 5(5):487-97. doi:10.1016/j.chom.2009.05.002

59. Gantner BN, Simmons RM, Canavera SJ, Akira S, Underhill DM. Collaborative induction of inflammatory responses by dectin-1 and toll-like receptor 2 . J Exp Med (2003) 197(9):1107-17. doi:10.1084/jem.20021787

60. Gross O, Gewies A, Finger K, Schäfer M, Sparwasser T, Peschel C, et al. Card9 controls a non-TLR signalling pathway for innate anti-fungal immunity. Nature (2006) 442(7103):651-6. doi:10.1038/nature04926

61. Whitney PG, Bär E, Osorio F, Rogers NC, Schraml BU, Deddouche S, et al. Syk signaling in dendritic cells orchestrates innate resistance to systemic fungal infection. PLoS Pathog (2014) 10(7):e1004276. doi:10.1371/journal. ppat. 1004276

62. Latz E, Xiao TS, Stutz A. Activation and regulation of the inflammasomes. Nat Rev Immunol (2013) 13(6):397-411. doi:10.1038/nri3452

63. Bruno VM, Shetty AC, Yano J, Fidel PL Jr, Noverr MC, Peters BM. Transcriptomic analysis of vulvovaginal candidiasis identifies a role for the NLRP3 inflammasome. MBio (2015) 6(2):e182-215. doi:10.1128/ mBio.00182-15

64. Gabrielli E, Pericolini E, Luciano E, Sabbatini S, Roselletti E, Perito S, et al. Induction of caspase-11 by aspartyl proteinases of Candida albicans and implication in promoting inflammatory response. Infect Immun (2015) 83(5):1940-8. doi:10.1128/IAI.02895-14

65. Bendel CM, Hess DJ, Garni RM, Henry-Stanley M, Wells CL. Comparative virulence of Candida albicans yeast and filamentous forms in orally and intravenously inoculated mice. Crit Care Med (2003) 31(2):501-7. doi:10.1097/01. CCM.0000049954.48239.A1

66. Wellington M, Koselny K, Krysan DJ. Candida albicans morphogenesis is not required for macrophage interleukin lbeta production. MBio (2012) 4(1):e412-33. doi:10.1128/mBio.00433-12

67. Borghi M, De Luca A, Puccetti M, Jaeger M, Mencacci A, Oikonomou V, et al. Pathogenic NLRP3 inflammasome activity during Candida infection is negatively regulated by IL-22 via activation of NLRC4 and IL-1Ra. Cell Host Microbe (2015) 18(2):198-209. doi:10.1016/j.chom.2015.07.004

68. Deeks SG. HIV infection, inflammation, immunosenescence, and aging. Annu Rev Med (2011) 62:141-55. doi:10.1146/annurev-med-042909-093756

69. Nixon DE, Landay AL. Biomarkers of immune dysfunction in HIV. Curr Opin HIV AIDS (2010) 5(6):498-503. doi:10.1097/COH.0b013e32833ed6f4

70. UNAIDS. Understanding UNAIDS HIV Data and Estimates. Geneva: WHO (2016).

71. Pontillo A, Brandão LA, Guimarães RL, Segat L, Athanasakis E, Crovella S. A 3'UTR SNP in NLRP3 gene is associated with susceptibility to HIV-1 infection. J Acquir Immune Defic Syndr (2010) 54(3):236-40. doi:10.1097/ QAI.0b013e3181dd17d4

72. Nasi M, De Biasi S, Bianchini E, Digaetano M, Pinti M, Gibellini L, et al. Analysis of inflammasomes and antiviral sensing components reveals decreased expression of NLRX1 in HIV-positive patients assuming efficient antiretroviral therapy. AIDS (2015) 29(15):1937-41. doi:10.1097/ QAD.0000000000000830

73. Pontillo A, Silva LT, Oshiro TM, Finazzo C, Crovella S, Duarte AJ, et al. HIV-1 induces NALP3-inflammasome expression and interleukin-1beta secretion in dendritic cells from healthy individuals but not from HIV-positive patients. AIDS (2012) 26(1):11-8. doi:10.1097/QAD.0b013e32834d697f

74. Chattergoon MA, Latanich R, Quinn J, Winter ME, Buckheit RW III, Blankson JN, et al. HIV and HCV activate the inflammasome in monocytes and macrophages via endosomal toll-like receptors without induction of 
type 1 interferon. PLoS Pathog (2014) 10(5):e1004082. doi:10.1371/journal. ppat. 1004082

75. Thomas C. Roadblocks in HIV research: five questions. Nat Med (2009) 15(8):855-9. doi:10.1038/nm0809-855

76. Galloway NL, Doitsh G, Monroe KM, Yang Z, Muñoz-Arias I, Levy DN, et al. Cell-to-cell transmission of HIV-1 is required to trigger pyroptotic death of lymphoid tissue-derived CD4 T cells. Cell Rep (2015) 12(10):1555-63. doi:10.1016/j.celrep.2015.08.011

77. Lou Y, Qesmi R, Wang Q, Steben M, Wu J, Heffernan JM. Epidemiological impact of a genital herpes type 2 vaccine for young females. PLoS One (2012) 7(10):e46027. doi:10.1371/journal.pone.0046027

78. Bernard HU, Burk RD, Chen Z, van Doorslaer K, zur Hausen H, de Villiers EM. Classification of papillomaviruses (PVs) based on 189 PV types and proposal of taxonomic amendments. Virology (2010) 401(1):70-9. doi:10.1016/ j.virol.2010.02.002

79. Lacey CJ, Lowndes CM, Shah KV. Chapter 4: burden and management of non-cancerous HPV-related conditions: HPV-6/11 disease. Vaccine (2006) 24(Suppl 3):S3/35-41. doi:10.1016/j.vaccine.2006.06.015

80. Tapsall JW. Antibiotic resistance in Neisseria gonorrhoeae. Clin Infect Dis (2005) 41(Suppl 4):S263-8. doi:10.1086/430787

81. Fichorova RN, Desai PJ, Gibson FC III, Genco CA. Distinct proinflammatory host responses to Neisseria gonorrhoeae infection in immortalized human cervical and vaginal epithelial cells. Infect Immun (2001) 69(9):5840-8. doi:10.1128/IAI.69.9.5840-5848.2001

82. Harvey HA, Post DM, Apicella MA. Immortalization of human urethral epithelial cells: a model for the study of the pathogenesis of and the inflammatory cytokine response to Neisseria gonorrhoeae infection. Infect Immun (2002) 70(10):5808-15. doi:10.1128/IAI.70.10.5808-5815.2002

83. Zhou X, Gao X, Broglie PM, Kebaier C, Anderson JE, Thom N, et al. Hexaacylated lipid A is required for host inflammatory response to Neisseria gonorrhoeae in experimental gonorrhea. Infect Immun (2014) 82(1):184-92. doi:10.1128/IAI.00890-13

84. Hughes FM Jr, Vivar NP, Kennis JG, Pratt-Thomas JD, Lowe DW, Shaner BE, et al. Inflammasomes are important mediators of cyclophosphamide-induced bladder inflammation. Am J Physiol Renal Physiol (2014) 306(3):F299-308. doi:10.1152/ajprenal.00297.2013

85. Wang C, Mendonsa GR, Symington JW, Zhang Q, Cadwell K, Virgin HW, et al. Atg16L1 deficiency confers protection from uropathogenic Escherichia coli infection in vivo. Proc Natl Acad Sci U S A (2012) 109(27):11008-13. doi:10.1073/pnas.1203952109

86. Schaale K, Peters KM, Murthy AM, Fritzsche AK, Phan MD, Totsika M, et al. Strain- and host species-specific inflammasome activation, IL-1beta release, and cell death in macrophages infected with uropathogenic Escherichia coli. Mucosal Immunol (2016) 9(1):124-36. doi:10.1038/mi.2015.44

87. Yang HH, Jun HK, Jung YJ, Choi BK. Enterococcus faecalis activates caspase-1 leading to increased interleukin-1 beta secretion in macrophages. JEndod (2014) 40(10):1587-92. doi:10.1016/j.joen.2014.06.015

88. Willingham SB, Allen IC, Bergstralh DT, Brickey WJ, Huang MT, Taxman DJ, et al. NLRP3 (NALP3, cryopyrin) facilitates in vivo caspase-1 activation, necrosis, and HMGB1 release via inflammasome-dependent and -independent pathways. J Immunol (2009) 183(3):2008-15. doi:10.4049/jimmunol. 0900138

89. Cai S, Batra S, Wakamatsu N, Pacher P, Jeyaseelan S. NLRC4 inflammasome-mediated production of IL-1beta modulates mucosal immunity in the lung against Gram-negative bacterial infection. JImmunol (2012) 188(11):5623-35. doi:10.4049/jimmunol.1200195

90. Nagamatsu K, Hannan TJ, Guest RL, Kostakioti M, Hadjifrangiskou M, Binkley J, et al. Dysregulation of Escherichia coli alpha-hemolysin expression alters the course of acute and persistent urinary tract infection. Proc Natl Acad Sci U S A (2015) 112(8):E871-80. doi:10.1073/pnas.1500374112

91. Craven RR, Gao X, Allen IC, Gris D, Bubeck Wardenburg J, McElvaniaTekippe E, et al. Staphylococcus aureus $\alpha$-hemolysin activates the NLRP3inflammasome in human and mouse monocytic cells. PLoS One (2009) 4(10):e7446. doi:10.1371/journal.pone.0007446

Conflict of Interest Statement: The authors declare that the research was conducted in the absence of any commercial or financial relationships that could be construed as a potential conflict of interest.

Copyright $\odot 2016$ Verma, Dhanda, Møller and Yadav. This is an open-access article distributed under the terms of the Creative Commons Attribution License (CC BY). The use, distribution or reproduction in other forums is permitted, provided the original author(s) or licensor are credited and that the original publication in this journal is cited, in accordance with accepted academic practice. No use, distribution or reproduction is permitted which does not comply with these terms. 